\title{
Efectos del Bloque de Constitucionalidad en materia de prescripción de la acción penal en Colombia*
}

\section{Constitutional BlocEffects of prescription of penal prosecution in Colombia}

Recibido: 16 de julio de 2009 - Revisado: 23 de julio de 2009 - Aceptado: 30 de octubre de 2009

\author{
Luis Andrés Fajardo Arturo*
}

\begin{abstract}
Resumen
En Colombia, los artículos 93, 94 y 214 de la Carta Constitucional crean un puente de implementación a través del cual el Derecho Internacional de los Derechos Humanos y el Derecho Internacional Humanitario se integran en el Derecho colombiano en virtud de la figura del Bloque de Constitucionalidad. El efecto principal de ello es la adaptación del derecho interno a los compromisos internacionales del Estado, y por consecuencia, la evolución en materia de protección y garantía de los Derechos Humanos en el ámbito interno.

Sin embargo, el proceso de implementación puede generar problemas complejos que se derivan, por ejemplo, de las contradicciones entre normas de derecho interno que se fundamentan en principios jurídicos arraigados en el país y las reglas del bloque de constitucionalidad. El caso de la prescripción de la acción penal en Colombia es un caso complejo, pero la normatividad internacional es clara en la existencia de una regla sobre la imprescriptibilidad de la acción penal de los crímenes de guerra y de lesa humanidad. El presente artículo es la conclusión sobre el examen de ponderación de los principios que allí se encuentran.
\end{abstract}

Palabras claves

Derecho Internacional de los Derechos Humanos, Derecho Internacional Humanitario, prescripción.

\begin{abstract}
In Colombia, the articles 93, 94 and 214 of the Constitutional Charter create a bridge of implementation through the International Law of Human Rights and International Humanitarian Law are integrated into the Colombian law under the figure of the Constitutional Bloc. The main effect of this is to adapt the internal law to the international obligations of the State, and consequently, the evolution in the protection and guarantee of human rights domestically.

However, the implementation process can generate complex problems that arise, for example, the contradictions between the rules of law which are based on legal principles rooted in the country and the bloc of of constitutionality's rules. The case of prescription of prosecution in Colombia is a complex case, but international norms is evident in the existence of a rule on the applicability of prosecution of war crimes and crimes against humanity. This article is the conclusion of a balance of the principles found there.

Key words

International Law of Human Rights, International Humanitarian Law, prescription.
\end{abstract}

\footnotetext{
* Artículo resultado de investigación del Grupo De las Casas, de la Universidad Sergio Arboleda.

** Director del Grupo de Investigaciones De las Casas, de la Universidad Sergio Arboleda. Abogado, magíster en Derecho Internacional Público de la Universidad París 2, magíster en Derecho de la Universidad Sergio Arboleda, especialista en DDHH y DIH de la Universidad Alcalá de Henares. Correo electrónico: andres.fajardo@usa.edu.co
} 


\section{Introducción}

El objetivo principal de la investigación es el determinar si en Colombia opera la regla internacional según la cual el crimen de genocidio, los crímenes de guerra y de lesa humanidad son imprescriptibles, teniendo en cuenta que no existe ninguna norma nacional que lo contemple.

Este problema general representa a su vez el abordaje de distintos problemas específicos como son: 1. La inviolabilidad del principio de legalidad en materia penal, en el entendido de que aplicar una regla de prescripción inexistente violaría el principio de la ley previa en materia penal. 2. La inviolabilidad del principio de favorabilidad en materia penal o la prioridad de una norma de Derecho Internacional frente al principio, $\mathrm{y}$, finalmente 3. La temporalidad a partir de la cual se puede admitir una regla de Derecho Internacional sobre imprescriptibilidad, teniendo en cuenta que la figura del Bloque de Constitucionalidad nació en la Constitución de 1991.

El abordaje del problema presentado representa una necesidad en un momento en el que Colombia está pasando por un proceso trascendental de justicia transicional en el que se ventila toda una serie de delitos que constituyen lo que internacionalmente se denominan crímenes de guerra y crímenes de lesa humanidad, y debe por lo tanto enfrentarse al dilema de permitir la impunidad frente a esos delitos para resguardar el ordenamiento penal interno, o sobrepasar las reglas del derecho penal nacional con el fin de adaptarse a los estándares internacionales en la materia y privilegiar así los derechos de las víctimas.

Fuera de la coyuntura que significa el proceso de Justicia y Paz, lo cierto es que Colombia no puede dejar que su normatividad interna y sus compromisos internacionales se contraríen y por lo tanto es indispensable que se establezcan reglas claras sobre el funcionamiento y la aplicación del Bloque de Constitucionalidad en materias de derecho penal en Colombia.

\section{Metodología}

La investigación que de la cual es resultado la presente ponencia fue realizada a través de un método comparado-dialéctico. Se partió del estudio del marco teórico sobre el tema en cuestión analizando el estado del arte en materia de Bloque de Constitucionalidad, influencia del Derecho Internacional en el derecho penal colombiano y en materia de ponderación de principios. Posteriormente, se realizó un barrido de la jurisprudencia de la Corte Constitucional colombiana, la Corte Interamericana de Derechos Humanos y la doctrina en materia de Derecho penal internacional; finalmente se estudiaron sentencias del derecho penal de Argentina y Perú como ejemplos de derecho comparado aplicables en Colombia.

Lainvestigación surge de una problemática identificada por el Grupo de Investigación De las Casas, en una investigación preliminar realizada con fiscales de la Unidad Nacional de Fiscalías para la Justicia y la Paz, así como con magistrados de Justicia y Paz, a través de la participación en talleres realizados por el proyecto Profis, de la Embajada de la República Alemana, y administrados por la GTZ1. En dichos talleres, y luego de las entrevistas realizadas, se encontró que uno de los retos principales para los operadores judiciales es la aplicación del Bloque de Constitucionalidad y en especial la solución a los conflictos que surgen del choque entre el Derecho Internacional y el Derecho penal colombiano en temas como la prescripción penal y el principio de legalidad.

En consecuencia de lo anterior, luego de los resultados logrados, la investigación se estructuró de tal forma que se pudiera determinar el estándar internacional en la materia y su valor jurídico a fin de confrontarlo con el derecho nacional y determinar el grado de vinculatoriedad frente al Derecho colombiano. 


\section{Resultados}

\section{Exigibilidad de las reglas internacionales en Colombia}

\section{Estructura del Derecho Internacional}

El primer punto a tratar para poder analizar el valor jurídico y aplicabilidad que tienen los estándares internacionales en Colombia surge de la naturaleza jurídica de los mismos.

Tradicionalmente, se denominan estándares internacionales en materia de Derechos Humanos y DIH al conjunto de reglas decantadas por la doctrina o la jurisprudencia internacional al analizar instrumentos internacionales: tratados y costumbres internacionales que se refieren a Derechos Humanos o Derecho Internacional Humanitario. Dichos instrumentos hacen parte de un sistema jurídico distinto al derecho nacional, cuya diferencia fundamental radica en que ni los sujetos de las obligaciones, ni los medios de exigibilidad son similares a aquellos establecidos por cualquier país para su derecho interno.

Los tratados internacionales en materia de Derechos Humanos son convenios realizados entre Estados bajo las reglas consignadas en la convención de Viena de 1969 en materia de tratados (: Art. 2.a), de forma que la vigilancia sobre su cumplimiento se hace bajo las reglas comunes del Derecho Internacional público. Ello implica que los responsables por el cumplimiento de las obligaciones que allí se consignan son los Estados signatarios frente a los cuales el tratado en cuestión ha entrado en vigor, y en consecuencia significa que los sujetos afectados con la violación de las obligaciones allí consignadas son los demás Estados Parte en el tratado, lo que les legitima para exigir el cumplimiento si así lo estiman necesario.

Se trata por lo tanto (desde la perspectiva de la escuela clásica) de un sistema jurídico en que los Estados se reconocen mutuamente derechos, implicando para ellos la obligación de respetarlos (Combacou; Serge, 1997). Un sistema en el que los sujetos jurídicos son los Estados, eventualmente también las organizaciones internacionales, y por lo tanto los particulares no pueden exigir el cumplimiento de las obligaciones allí pactadas, porque no son ellos los sujetos de las mismas.

En estricto sentido, los tratados en materia de derechos humanos -por lo menos en la concepción clásica y voluntarista del Derecho Internacional- generan obligaciones interestatales consistentes en respetar los Derechos Humanos de los particulares que se encuentren bajo su jurisdicción (Dupuy Pierre-Marie, 1995). Puesto que la obligación surge entre los Estados, son ellos los únicos capacitados para exigirla internacionalmente.

Ese eselsentidobajoel cualseconstruyeron las bases del Sistema Interamericano, de forma tal que quien puede presentar la demanda ante la Corte Interamericana de Derechos Humanos es un Estado Parte o la Comisión Interamericana, esta última en tanto es un órgano de la OEA, es decir, representa a una persona jurídica internacional. Lo cierto es que por lo menos hasta ahora, a pesar de que la evolución del Reglamento de la Corte ha ido reconociendo derechos procesales a las víctimas, un particular no puede presentar directamente la demanda ante la Corte Interamericana de Derechos Humanos (OEA, 1969:Art. 61).

Tampoco es posible presentar una demanda por violación de uno de los Pactos de Ginebra sobre Derecho Internacional Humanitario (DIH) o respecto de cualquier otro tratado sobre la materia por parte de un particular, un grupo de particulares o una $\mathrm{ONG}$, ante la Corte Internacional de Justicia (ONU, 1945:Art.34.1).

Es, pues, importante plantear el problema para poder entender con claridad la dimensión y complejidad del tema de estudio. El Derecho 
Internacional de los Derechos Humanos (DIDH) y el DIH consagran obligaciones y estándares que en principio, al menos, son exigibles únicamente entre Estados.

Desde luego que no es el objetivo del DIDH ni del DIH el crear normas sin contenido. Es evidente que los beneficiarios y verdaderos interesados en el cumplimiento de las obligaciones consagradas en esos instrumentos no son los Estados sino los particulares, por lo tanto, también es claro que de nada servirían esas normas si no estuvieran dirigidas a producir efectos en el derecho interno o si no se crearan medios para que los particulares pudieran exigir su cumplimiento.

\section{La relación entre Derecho Interno y Derecho Internacional en Colombia}

$\mathrm{Si}$ bien las normas de Derecho Internacional público están dirigidas a regular las relaciones entre los sujetos de la "sociedad internacional" (Pellet, 2001) bajo el concepto del principio ubis societas ibi jus, lo cierto es que en el derecho interno dichas normas también pueden tener un valor jurídico específico, dependiendo de cuál sea el modelo adoptado por el Estado en materia de la relación que el Derecho Internacional, y en especial los tratados ratificados por el Estado tienen con el derecho interno.

Las teorías y posiciones estatales pueden clasificarse dependiendo de si el Estado considera que se trata de dos sistemas jurídicos completamente independientes -dualismo- o si se trata de un solo sistema con primacía del derecho interno o del Derecho Internacional -monismo- o un solo sistema sin una primacía bien definida -monismo moderado- (Monroy, 2002 : P.136).

En Colombia la posición adoptada sobre la relación entre los dos sistemas jurídicos es, al menos desde el siglo pasado, la del monismo constitucionalista. Sin embargo, la figura del
Bloque de Constitucionalidad ha cambiado la jerarquía de las normas en el Derecho colombiano, convirtiéndolo en un sistema de monismo moderado, en el que la primacía de la Constitución no excluye la primacía de ciertas normas del Derecho Internacional.

Así lo expresó la Corte Constitucional en la Sentencia C-225/96, explicando que en Colombia, en virtud de lo expuesto por el artículo 4 de la Constitución Política Colombiana, el derecho interno tenía una primacía absoluta, y los tratados pueden tener igual valor, en virtud de que algunos de ellos hacen parte del Bloque de Constitucionalidad. De tal manera que lo que se aplica en el derecho interno no es el tratado en sí mismo, sino la Constitución Nacional, que en algunos casos está conformada por normas de tratados internacionales ratificados por Colombia.

\section{Herramientas de integración del Derecho Internacional en Colombia}

Desde una perspectiva monista, la sistematicidad del derecho hace necesaria la existencia de reglas que permitan implementar y dar un valor jerárquico específico en el sistema jurídico nacional a las reglas del Derecho Internacional. Cada Estado establece la forma en que se articulan dichas reglas, generando mayor o menor valor y grado de efectividad a las normas internacionales según sus propias necesidades y perspectivas.

La regla de integración del Derecho Internacional en Colombia es principalmente la que se establece en los artículos 93, 94 y 214 de la Constitución Colombiana que se ha denominado como Bloque de Constitucionalidad. En este caso, las normas del tratado entran a hacer parte del derecho interno y son exigibles en tanto son parte de la Constitución Nacional, por lo que además de ser exigibles en el derecho interno, lo son con el más alto rango jurídico.

LanocióndelBloquedeConstitucionalidad se fundamenta principalmente en la redacción 
del artículo 93 de la Constitución. Al analizarlo, la Corte ha manifestado que existe una relación diferenciada entre los dos incisos que lo componen. Por una parte, el primer inciso "permite incorporar ciertos derechos y principios al bloque de constitucionalidad, incluso cuando éstos no han sido reconocidos por el articulado constitucional, pero para ello se requiere que sean derechos no limitables en estados de excepción", mientras que en el segundo inciso "tiene otra finalidad pues esa norma completa y dinamiza el contenido protegido de un derecho que ya está consagrado en la Carta, puesto que, conforme a ese inciso, tal derecho debe ser interpretado de conformidad con los tratados ratificados por Colombia" (Sentencia. T-1318/01).

Esta tesis, sostenida en la sentencia T-1319 de 2001 y reiterada por la Corte en sentencias de unificación como 058/03 y 067/03, se traduce en que por una parte, el artículo 93 permite la inclusión de nuevos derechos en el corpus iuris constitucional y, por otra, para los derechos reconocidos en la Carta, hace necesaria una valoración a la luz de los tratados firmados por Colombia (Sentencia. T-1319/01, p.17).

Pero la posición más interesante sostenida en la $\mathrm{T}-1319 / 01$, que se reitera en varias sentencias, es aquella según la cual el inciso 2 del artículo 93 establece una forma de incorporación vía interpretación "en que ha de fundirse la norma nacional con la internacional y acogerse la interpretación que las autoridades competentes hacen de las normas internacionales e integrar dicha interpretación al ejercicio hermenéutico de la Corte" $"$

\section{Requisitos de operación del Bloque de Constitucionalidad}

La validez del Bloque de Constitucionalidad en Colombia se debe a que, según lo ha venido sosteniendo la Corte de forma reiterada, "existe remisión expresa de la Constitución” (Sentencia. C-578/95, p.28), $\mathrm{y}$ en ese sentido, para que una norma sea válidamente usada como parte del Bloque, debe cumplir con los requisitos que exige el artículo 93 de la Carta.

Para que opere "la prevalencia en el orden interno de ciertos contenidos de los tratados de Derechos Humanos ratificados por Colombia es necesario que se den los dos supuestos a la vez, de una parte, el reconocimiento de un derecho humano, y de la otra, que sea de aquellos cuya limitación se prohíba durante los estados de excepción". Esta posición establecida desde la Sentencia C-295/93 constituye un precedente fuertemente reiterado ${ }^{3}$, aunque, como se verá más adelante, este requisito no ha sido exigido estrictamente en todos los casos.

\section{Utilización del criterio interamericano por la Corte Constitucional Colombiana}

El Sistema Interamericano es, ante todo, una evolución hacia lo jurisdiccional desde lo político. El Sistema es el resultado de la Declaración Americana, que nació paralelamente a la OEA. Su implementación se tradujo en la necesidad de la creación de un órgano de vigilancia que se encargara de vigilar las situaciones en el continente y poner al tanto a la Asamblea General de la OEA de lo que sucedía, mientras poco a poco se iba interesando de casos particulares (Medina; Nash, 2007).

Las consecuencias derivadas de la adhesión de Colombia al Sistema Interamericano ${ }^{4}$ se materializan en la obligación de adelantar el establecimiento de políticas en los diversos órganos y ramas del Estado, tendientes a la promulgación, protección y garantía efectiva de los Derechos Humanos en los distintos escenarios en que entran en juego.

En ese sentido, es posible sostener que en Colombia la libertad de configuración legislativa no es absoluta, ni tampoco la interpretación y aplicación de la ley por los operadores judiciales al momento de decidir. Las medidas, 
actos y operaciones administrativas tampoco están exentas del examen de concordancia con aquellos preceptos integrantes del bloque de constitucionalidad que surgen del corpus iuris interamericano.

El medio en que esta afectación jurídica sucede, el puente de comunicación entre el orden jurídico y todo el establishment del Estado colombiano frente al Sistema Interamericano no es, ni puede ser otro, que el Derecho Constitucional derivado.

El valor jurídico implicado de este derecho constitucional derivado surge principalmente de que la misma Corte Constitucional se ha reconocido como obligatoria en sus precedentes, determinando un valor de fuente formal de derecho a sus interpretaciones judiciales, convirtiendo al Bloque y en especial a su contenido en materia interamericana, en una parte más del derecho constitucional positivo en el país.

El Bloque de Constitucionalidad constituye la herramienta de integración del Derecho Interamericano en Colombia, pero en realidad, esa herramienta carece per se de concreción en sus efectos. El Bloque, tal como está descrito en el artículo 93 de la Carta Constitucional, bien podría haber sido usado de forma restrictiva y haberse quedado en la reiteración de los derechos fundamentales de la Constitución, ergo, no significar ampliación alguna de la misma.

Es por lo tanto el ejercicio jurisdiccional del juez constitucional el que, a través de sus productos respecto de la interpretación de los Derechos Humanos, se ha dado a la tarea de darle al Bloque un rol de protagonista en el Derecho colombiano.

\section{Reglas de implementación del Bloque en derecho penal}

El Sistema Jurídico preponderante en la actualidad colombiana es el que se comparte con el resto de la Latinoamérica contemporánea, un sistema basado en el modelo neoconstitucionalista, que se fundamenta en la prevalencia de la Constitución en el ordenamiento jurídico y en la aplicabilidad directa de las normas constitucionales en el derecho nacional.

En ese sentido, no se puede dejar de lado que la implicación primera de la adopción de un sistema neoconstitucionalista es que todo el ordenamiento jurídico nacional debe estar acorde con los postulados constitucionales a riesgo de que cualquier norma que no lo esté sea declarada inexequible por su inconstitucionalidad.

Esta regla general, que en Colombia tiene una especial importancia debido fundamentalmente al modelo que pone en práctica la Corte Constitucional a través de un examen constante y riguroso de la normatividad a la luz de la Constitución, no implica, por tanto, que la consideración de exequibilidad de las normas nacionales pueda estar en cabeza de cualquier ciudadano.

La presunción de constitucionalidad de la ley prima ante cualquier circunstancia. El control de constitucionalidad no está en cabeza de cualquier persona, ni el procedimiento en que se adelanta es informal. Existen unas fórmulas concretas para hacer que una norma legalmente establecida deje de prestar efectos jurídicos por estar en contra de la Constitución, pero fuera de ese procedimiento, reglado y estricto, no puede dejar de desconocerse la ley interna so pretexto de que es contraria a la Constitución.

En ese mismo sentido, el Bloque de Constitucionalidad, que no es otra cosa que una parte más de la Constitución Nacional, no puede servir para desconocer las normas nacionales de menor jerarquía, que previo examen de constitucionalidad y declaratoria de inexequibilidad por un juez competente (por vía acción o excepción).

Esta regla fundamental para sostener el Estado de Derecho y garantizar el respeto por la 
seguridad jurídica, así como finalmente por los derechos de los ciudadanos, no es una posición regresiva frente a la importancia del Bloque de Constitucionalidad, sino por el contrario, la reiteración de la importancia del mismo a través de la consolidación de las reglas de uso.

\section{Derecho Penal Colombiano vs. Bloque de Constitucionalidad}

Algunos autores podrían sostener que existe una tensión entre las normas del derecho interno con las normas del Derecho Internacional y que la forma de resolverlo es utilizar las normas de este porque hacen parte del Bloque de Constitucionalidad.

Esta solución es totalmente viable, siempre y cuando serespete la regla que antes se expuso: las normas de menor jerarquía son válidas mientras no exista un juicio de inconstitucionalidad que las deje sin competencia o un pronunciamiento directo de la Corte Constitucional que las declare inexequibles.

Dicho juicio de inconstitucionalidad implica una serie de pasos complejos que no pueden dejarse al libre arbitrio de todo ciudadano. Para poder establecer que una norma del derecho interno es inconstitucional por ir en contra del Bloque de Constitucionalidad habría que preguntarse:

1. ¿La norma de Derecho Internacional supuestamente controvertida hace parte del Bloque de Constitucionalidad?

Para responder esta pregunta habría que preguntarse, en primer lugar, si la Corte Constitucional ya ha hecho mención al respecto (téngase en cuenta que la Corte ya se ha referido a la casi totalidad de normas que hacen parte del Bloque). Si la Corte no se hubiere pronunciado, habrá que establecer que hace parte de los Derechos Humanos irrestringibles en materia de Estados de Excepción contemplados en un tratado ratificado por Colombia. Aun queda la posibilidad de que no siendo de estas normas, se trate de uno de los Convenios de Ginebra o de la Organización Internacional del Trabajo (OIT). Finalmente, es posible que se trate de una norma internacional que desarrolle uno de los Derechos Fundamentales de la Constitución, lo cual serviría para ampliar su contenido, para lo que habría que estudiar el instrumento en el que se encuentra y su valor vinculante frente a Colombia. En caso contrario, lo más posible es que la norma no haga parte del Bloque de Constitucionalidad.

2. ¿Existe una contradicción objetiva entre la norma internacional y la norma interna?

La dificultad más grande en una demanda de inconstitucionalidad o una excepción de inexequibilidad radica en establecer que la contradicción entre las normas no se sustenta en una apreciación subjetiva de las mismas, o en interpretaciones libres, sino que se trata de contradicciones objetivas y comprobables en que el sentido real de una norma de mayor jerarquía es incompatible con la existencia de la norma inferior. Esto implica que se debe tener una total claridad en el contenido de cada postulado internacional limitándose, para ello, al sentido exacto de la norma y no a las interpretaciones de la doctrina.

En ese sentido, tampoco se puede predicar la inconstitucionalidad de una norma como base en las prácticas que de ella se haga. Es importante recalcar tal como lo hace el profesor Ibáñez Najar (2005), que no es por la vía de la declaratoria de inexequibilidad de una norma por la que se debe acudir en caso de que la interpretación o aplicación de la misma genere efectos contrarios a los postulados constitucionales, pues para ello existen otras vías destinadas a lograr cambios en la jurisprudencia o a generar interpretaciones de autoridad.

Habida cuenta de lo aquí expuesto, es debido sostener que la jurisdicción penal nacional tiene plena vigencia mientras no 
haya un pronunciamiento judicial claro que la contraríe.

Ahora bien, la pregunta se puede formular y es en la práctica más usual que se formule de otra manera:

3. ¿Cómo debe proceder el funcionario judicial cuando existe una interpretación autorizada por parte de la Corte Constitucional que contraría el sentido natural de una norma del Código Penal?

A partir de la sentencia C-836 de 2001, la Honorable Corte Constitucional ha venido sosteniendo que su jurisprudencia tiene el carácter de precedente vinculante en el ámbito nacional. Esta situación, acorde con el modelo neoconstitucionalista, implica un giro brusco en el devenir de la práctica jurídica colombiana, tan profundamente imbuida de los postulados iuspositivistas.

Siendo esto así, la jurisprudencia constitucional debe aplicarse preferentemente a los postulados que le sean contrarios, sin embargo, para que esto pueda ser legítimo, debe existir un grado de certeza suficientemente alto respecto de la existencia de la posición de la Corte frente al tema de debate.

En este punto, es importante sostener que no puede existir una duda legítima que sustente la inaplicación de una norma vigente por parte del funcionario judicial sino que existe una jurisprudencia clara y en lo posible reiterada, que en un sentido unívoco especifique una regla distinta al sentido en que se aplicaría la norma en cuestión.

Para ello es indispensable tener un conocimiento actualizado sobre la jurisprudencia que la Corte va generando respecto de las normas penales.

En cualquier caso, una interpretación ambigua, equivoca o realizada en razón de un argumento no equiparable a aquel que se examina, no puede servir de sustento para dejar de aplicar una norma vigente. Por ello, sólo se puede hacer uso de la jurisprudencia para dejar de aplicar una norma, cuando exista cosa juzgada constitucional al respecto, cuando exista un pronunciamiento en que la ratio decidendi sea aplicable al caso sub lite por haber entre los dos casos coincidencia evidente en los elementos fundamentales que motivan la decisión, o por haberse generado una subregla confirmada por la Corte y aplicable al caso en concreto.

\section{Análisis de la imprescriptividad en materia penal}

El artículo 83 del Código Penal (Ley 599 de 2000) establece que el término máximo de prescripción de la acción penal en Colombia es de 20 años, con excepción de lo dicho en su inciso segundo según el cual "el término de prescripción para las conductas punibles de genocidio, desaparición forzada, tortura y desplazamiento forzado será de treinta (30) años".

Ello significa que en Colombia los crímenes de guerra, de lesa humanidad y las graves violaciones de Derechos Humanos tienen un término de prescripción, lo que contraría los principios internacionales al respecto.

Debe entenderse por principios de Derecho Internacional los enunciados normativos más generales que, sin haber sido integrados al ordenamiento jurídico en virtud de procedimientos formales, forman parte de él, porque les sirven de fundamento a otros enunciados normativos particulares.

En este punto, es necesario hacer alusión a los diferentes principios que existen para regular las relaciones entre los Estados, pero únicamente aquellos que se refieran a la imprescriptibilidad de los delitos de lesa humanidad y los que estén relacionados con el deber de los Estados de castigar a los responsables de estos delitos. 
Dentro del grupo de documentos que contienen los principios están:

1. Principios de cooperación internacional en la identificación, detención, extradición y castigo de los culpables de crímenes de guerra, o de crímenes de lesa humanidad (ONU, 1973).

2. Principios de derecho internacional reconocidos por el estatuto y por las sentencias del Tribunal de Nuremberg (ONU, 1950).

3. Conjunto de principios actualizado para la protección y promoción de los derechos humanos mediante la lucha contra la impunidad (ONU, 2005).

4. Principios y directrices básicos sobre el derecho de las víctimas de violaciones a las normas internacionales de derechos humanos y del Derecho Internacional Humanitario a interponer recursos y obtener reparaciones (ONU, 2007).

5. Principios de Bruselas contra la impunidad y por la justicia internacional (ONU, 2002).

Los principios de cooperación internacional en la identificación, detención, extradición y castigo de los culpables de crímenes de guerra, o de crímenes de lesa humanidad (ONU) fueron aprobados el 3 de diciembre de 1973 por la Asamblea General de la ONU.

En el artículo primero de este documento se establece que "los crímenes de guerra y los crímenes de lesa humanidad, donde quiera y cualquiera que sea la fecha en que se hayan cometido, serán objeto de investigación, y las personas contra las que existe pruebas de culpabilidad en la comisión de tales crímenes serán buscadas, detenidas, enjuiciadas $\mathrm{y}$, en caso de ser declaradas culpables, castigadas".
Por su parte, el artículo 8 impone la obligación a los Estados de no adoptar disposiciones legislativas o de cualquier otra índole, que puedan afectar las obligaciones internacionales con respecto a la identificación, detención, extradición y castigo de los responsables de los delitos antes mencionados.

Los principios de derecho internacional reconocidos por el estatuto y por las sentencias del Tribunal de Nuremberg (ONU) fueron aprobados por la Comisión de Derecho Internacional de las Naciones Unidas, en 1950.

Es necesario tener en cuenta que, a pesar de que en algunos casos no se sancione a los responsables de los crímenes de lesa humanidad y los crímenes de guerra debido a la prescripción de estos delitos, esta situación a la luz del Derecho Internacional y más específicamente en virtud de estos principios, no exime a la persona que cometió el delito, de su responsabilidad bajo las leyes internacionales, aun teniendo en cuenta la normatividad y decisiones tomadas a nivel interno ${ }^{5}$.

El conjunto de principios actualizado para la protección y promoción de los derechos humanos mediante la lucha contra la impunidad (ONU), ha establecido una serie de definiciones y directrices a seguir sobre las cuales es importante señalar las siguientes:

En el principio 23 establece expresamente la imprescriptibilidad de los delitos de lesa humanidad, cuando indica que "La prescripción no se aplicará a los delitos graves conforme el derecho internacional que sean por naturaleza imprescriptibles".

Ha sido de tal trascendencia el tema de la imprescriptibilidad, que la Comisión de Derechos Humanos de las Naciones Unidas vio la necesidad de crear en el año 2000 unos principios y directrices básicos sobre el derecho de las víctimas de violaciones de las normas internacionales de derechos humanos y del 
Derecho Internacional Humanitario a interponer recursos y obtener reparaciones.

Dicho instrumento afirma que los principios y directrices allí enunciados se aplican a las violaciones de normas internacionales de derechos humanos y a las violaciones graves del Derecho Internacional Humanitario.

Por último, los principios de Bruselas contra la impunidad y por la justicia internacional de las Naciones Unidas (2002).

La finalidad de este compendio de principios es combatir la impunidad, que provoca consecuencias desastrosas, ya que permite que los autores de graves crímenes contra la humanidad escapen de las sanciones por sus delitos, ignora la angustia de las víctimas y perpetúa la comisión de los crímenes.

Estos principios contra la impunidad se dividen en cinco grupos, y más específicamente en su principio número 7 establece la imprescriptibilidad, donde expresamente señala:

"1. Los crímenes de guerra, los crímenes contra la humanidad y el crimen de genocidio son imprescriptibles" (ONU, 2002: Ppio. 7).

\section{Normatividad respecto del DIH}

Por otra parte, en materia de Derecho Internacional Humanitario, uno de los instrumentos más relevantes sobre la imprescriptibilidad de los crímenes de guerra es la Lista de las normas consuetudinarias del Derecho Internacional Humanitario.

Dicha lista contiene 161 normas consuetudinarias sobre el Derecho Internacional Humanitario consuetudinario, las cuales deben ser aplicadas y tenidas en cuenta por todos los países, en búsqueda de proteger y respetar el DIH y los DDHH.

La norma de este instrumento que nos concierne para desarrollar el tema de esta demanda de inconstitucionalidad es la 160 , la cual consagra que "Las leyes de prescripción no se aplican a los crímenes de guerra” (CICR, 2007).

\section{Jurisprudencia de la Corte Interame- ricana de Derechos Humanos respecto la imprescriptibilidad}

En materia del Sistema Interamericano de Derechos Humanos, la Corte se ha pronunciado en múltiples ocasiones sobre la materia. En general, son dos los presupuestos que entran en juego en esta posición de la Corte:

En primer lugar, el concepto de impunidad, desarrollado por el tribunal desde sus inicios bajo estos términos: "La Corte entiende como impunidad la falta en su conjunto de investigación, persecución, captura, enjuiciamiento y condena de los responsables de las violaciones de los derechos protegidos por la Convención Americana, toda vez que el Estado tiene la obligación de combatir tal situación por todos los medios legales disponibles ya que la impunidad propicia la repetición crónica de las violaciones de Derechos Humanos y la total indefensión de las víctimas y de sus familiares"6.

En segundo lugar, se pone de presente el objetivo de dar efectividad a las disposiciones de la Convención. Los derechos contenidos en la Convención Americana necesitan de un esfuerzo del Estado para adecuar su legislación a los objetivos de la misma, en caso contrario la Convención y los compromisos con ella adquiridos se convierten en letra muerta. En ese sentido, no basta con que la actuación fáctica del Estado esté acorde con los postulados convencionales, sino que el valor axiológico de la Convención Americana implica igualmente que la legislación interna no se convierta en una barrera para la efectividad plena de los derechos consagrados en ella.

Tesisdecisionaldela CorteInteramericana respecto a la prescripción penal

La posición de la Corte IDH respecto de las leyes de prescripción ha sido constante 
en sostener que estas disposiciones no pueden servir de pretexto para fomentar la impunidad y dejar de cumplir con las obligaciones del Estado frente a la Convención respecto de los derechos de las víctimas. Sin embargo, y como se verá a continuación, existe una variación en la jurisprudencia respecto del alcance de esta obligación -la de eliminar las normas sobre prescripción- respecto del tipo de delito que se haya cometido.

En la primera posición tomada al respecto en el caso Barrios Altos C. Perú, la Corte IDH considera que "son inadmisibles las disposiciones de amnistía, las disposiciones de prescripción y el establecimiento de excluyentes de responsabilidad que pretendan impedir la investigación y sanción de los responsables de las violaciones graves de los Derechos Humanos tales como la tortura, las ejecuciones sumarias, extralegales o arbitrarias y las desapariciones forzadas, todas ellas prohibidas por contravenir derechos inderogables reconocidos por el Derecho Internacional de los Derechos Humanos" (Párr. 41).

Vale la pena resaltar que en esta primera ocasión, es en virtud de la naturaleza del delito -violaciones graves a los Derechos Humanospor lo que se convierten en inadmisibles las disposiciones de prescripción.

Inmediatamente, la jurisprudencia de la Corte reitera esta posición de forma exacta en la interpretación de la sentencia de fondo del caso Barrios Altos (2001: párr.15) y en las sentencias de reparaciones del caso Trujillo Oroza (CrIDH, 2002: párr. 106) ${ }^{7}$.

Posteriormente, en la sentencia del caso Bulacio C. Argentina en 2003, la Corte parece querer ampliar el ámbito de aplicación de la regla sustraída, estipulando en los párrafos 117 y 118 de dicha sentencia la regla según la cual:

De acuerdo con las obligaciones convencionales asumidas por los Estados, ninguna disposición o instituto de derecho interno, entre ellos la prescripción, podría oponerse al cumplimiento de las decisiones de la Corte en cuanto a la investigación y sanción de los responsables de las violaciones de los Derechos Humanos, si así no fuera, los derechos consagrados en la Convención Americana estarían desprovistos de una protección efectiva. Este entendimiento de la Corte está conforme a la letra y al espíritu de la Convención, así como a los principios generales del derecho; uno de estos principios es el de pacta sunt servanda, el cual requiere que a las disposiciones de un tratado le sea asegurado el efecto útil en el plano del derecho interno de los Estados Partes. (...) 118. De conformidad con los principios generales del derecho y tal como se desprende del artículo 27 de la Convención de Viena sobre el derecho de los tratados de 1969, las decisiones de los órganos de protección internacional de Derechos Humanos no pueden encontrar obstáculo alguno en las reglas o institutos de derecho interno para su plena aplicación.

Esta sentencia ha sido criticada por pretender ampliar el espectro de la imprescriptibilidad, no sólo a las graves violaciones de Derechos Humanos a que hacen referencia las demás sentencias sino en general a "las violaciones de Derechos Humanos", lo cual generaría una virtual desaparición de la regla de la prescripción de la acción penal.

\section{La posición de la Corte Constitucional Colombiana al respecto}

La Corte Constitucional ha tenido oportunidad de tocar tangencialmente el tema en cuestión en sentencias como la C-580 de 2002 en que trató sobre la constitucionalidad de la Convención Interamericana sobre Desaparición Forzada. 
En dicha sentencia la Corte ha encontrado razonable y justificado el que exista un régimen especial frente a los delitos que afectan gravemente la dignidad humana, sin embargo no ha declarado - pues no ha sido el objeto de las demandas- la inconstitucionalidad de las reglas generales sobre prescripción de la acción penal en Colombia.

En otras ocasiones, aunque en obiter dictum, la Corte Constitucional se ha pronunciado de forma tal que permite suponer una tendencia a la aceptación del principio internacional, así por ejemplo en la sentencia T-1033 /06 dijo: "A ello debe sumarse que en relación con las conductas mas graves -respecto de las cuales incluso como en el caso de la desaparición forzada la acción penal es imprescriptible- la norma permitiría con el simple cambio de competencia que tales delitos sean excluidos del listado de excepciones a la prescripción, previsto en el artículo 531 de la Ley 906 de 2004".

Este mismo argumento fue esbozado en la sentencia C-370 de 2006 sobre la constitucionalidad de la Ley de Justicia y Paz. Allí la Corte sostuvo "4.9.11.8. La acción penal es imprescriptible respecto de delitos como el de desaparición forzada de personas. Lo anterior por varias razones: el interés en erradicar la impunidad, la necesidad de que la sociedad y los afectados conozcan la verdad y se atribuyan las responsabilidades individuales e institucionales correspondientes, y en general que se garantice el derecho de las víctimas a la justicia y a la reparación por los daños".

\section{Conclusiones}

1. En primer lugar es necesario establecer que existe, con total certitud, una regla del Derecho Internacional Público según la cual la acción penal frente a los crímenes de genocidio, lesa humanidad y crímenes de guerra es imprescriptible, tal y como lo demuestran los principios generales de Derecho Internacional en la materia y como finalmente ha quedado estatuido en el Estatuto de Roma de 1998 y en una serie de principios reconocidos por la ONU y por la CICR que tendrían el valor jurídico de costumbre Internacional.

2. Ese principio se amplía a otras conductas que puedan considerarse como "graves violaciones a los Derechos Humanos" según lo ha establecido la jurisprudencia constante del Sistema Interamericano, la cual ha su vez ha sido múltiples veces citada por la Corte Constitucional como parte del Bloque de Constitucionalidad por tratarse de la interpretación autorizada de la Convención Americana sobre Derechos Humanos.

3. La Corte Constitucional se ha referido tangencialmente al tema dando algunas puntadas que darían muestra de una inclinación a la aceptación del principio, pero hasta ahora no se ha pronunciado de forma directa sobre la validez y aplicabilidad de esa regla en Colombia.

4. Los artículos del Código Penal que hacen referencia a la prescripción y que consagran reglas generales según las cuales un delito internacionalmente considerado como imprescriptible en Colombia es prescriptible, siguen estando vigentes en el derecho interno.

5. En vista de que no existe un pronunciamiento directo de la Corte Constitucional que haga referencia al valor de esa regla internacional en Colombia, ninguna autoridad que administre justicia puede desconocer las reglas de prescripción penal, ni siquiera frente a conductas internacionalmente consideradas como imprescriptibles, puesto que de otra manera estaría actuando ilícitamente.

6. Finalmente, siendo así, Colombia requiere inmediatamente un pronunciamiento de la Corte Constitucional en la materia a fin de evitar una responsabilidad Estatal por actuar de forma contraria a sus compromisos internacionales. 


\section{Notas}

${ }^{1}$ Los talleres realizados por la GTZProfis se adelantaron en los meses de febrero y marzo de 2009, en las ciudades de Santa Marta y Bogotá, con fiscales de la Unidad Nacional de Fiscalías para la Justicia y la Paz, y con magistrados de Justicia y Paz, en ellos se pudieron adelantar encuestas como parte de la investigación.

C-148/05.

2 Ver también sentencia T-666/04,

${ }^{3}$ Ratificado en las sentencias: C-225/95, C-578/95, C-327/97, Auto 078/99, C-582/99, T-1211/00, C-1490/00, C-1635/00, C-177/01, C-774/01, C-200/02, C-580/02， C-148/05, C-820/05, C-1001/05.

${ }^{4}$ Aprobada por Colombia mediante la Ley 16 de 1972. Derecho a la vida (artículo 4); derecho a la integridad personal (artículo 5); derecho a la libertad personal (artículo 7); prohibición de tratos crueles, inhumanos o degradantes (artículo 5); derecho a no ser detenido arbitrariamente (artículo 7).

${ }^{5}$ Artículos 1 y 2 de los Principios del Tribunal de Nuremberg.

6 Cfr., Caso Bulacio C. Argentina, párr. 120; Caso Las Palmeras C. Colombia, Reparaciones, párr. 53.a; y Caso del Caracazo C. Venezuela, Reparaciones, párr. 116 y 117.

${ }^{7} \mathrm{Cr}$ IDH, Sentencia sobre reparaciones, caso Trujillo Oroza C. Bolivia, del 27 de febrero de 2002. Párr. 106.

\section{Referencias}

CICR (2007), Derecho Internacional Humanitario Consuetudinario, Vol. 1.

Combancau, J. \& Serge, S. (2001). Droit International Public, Montchrestien, París.
Dupuy, P.M. (1995). Droit International Public, Dalloz, París.

López, D. (1997). Libertad y restricción en la decisión judicial. El debate con la teoría critica del derecho, Siglo del Hombre Editores, Bogotá.

Monroy, M. (2002). Derecho Internacional Público, Temis, Bogotá.

OEA (1969). Convención Americana sobre Derechos Humanos, San José.

ONU (1945). Estatuto de la Corte Internacional de Justicia, New York.

ONU. (1973). Principios de Cooperación Internacional en la Identificación, Detención, Extradición y Castigo de los Culpables de Crimenes de Guerra, o de Crímenes de Lesa Humanidad.

ONU (2002). Principios de Bruselas Contra la Impunidad y por la Justicia Internacional.

ONU (2005). 1. Conjunto de Principios Actualizado para la Protección y Promoción de los Derechos Humanos Mediante la Lucha Contra la Impunidad.

ONU (2005) 2. Principios y Directrices Básicos sobre el Derecho de las Victimas de Violaciones a las Normas Internacionales de Derechos Humanos y del Derecho Internacional Humanitario a Interponer Recursos y Obtener Reparaciones.

Pellet, A. (2003). Droit International Public, LGDJ, París.

Rodríguez, C. (2005). El caleidoscopio de las justicias en Colombia, Siglo del Hombre Editores, Bogotá.

Uprimny, R. (2005). La Unidiversalidad de los Derechos Humanos: Conflictos de derechos, conceptos de democracia e interpretación constitucional. Bogotá. 
